Eixo Temático: Biologia Aplicada

\title{
ET-09-024 \\ CARACTERIZAÇÃO AGRONÔMICA, QUANTIDADE E QUALIDADE DO MARACUJÁ-AZEDO NA REGIÃO DA SERRA DE CUITÉ
}

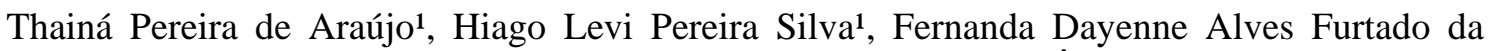
Costa $^{2}$, Wellington Sabino Adriano ${ }^{3}$, Magnólia de Araújo Campos ${ }^{3}$, Ângelo Kidelman Dantas ${ }^{3}$

${ }^{1}$ Discente. Licenciatura em Ciências Biológica e Bacharelada em Farmácia. Centro de Educação e Saúde (CES), Universidade Federal de Campina Grande (UFCG). E-mail: thaina.felipo@hotmail.com.

${ }^{2}$ Mestranda. Pós-graduação em Ciências Naturais e Biotecnologia. Centro de Educação e Saúde (CES), Universidade Federal de Campina Grande (UFCG).

${ }^{3}$ Docente. Pós-graduação em Ciências Naturais e Biotecnologia. Centro de Educação e Saúde (CES), Universidade Federal de Campina Grande (UFCG).

http://dx.doi.org/10.21472/congrebio2016.et-09-024

\section{RESUMO}

O presente trabalho tem como objetivo quantificar e caracterizar a produção de frutos de maracujá-azedo (Passiflora edulis Sims. f. flavicarpa Deg.) para fins de seleção das melhores plantas. Os dados foram coletados em sítios situados nas cidades de Coronel Ezequiel e Nova Floresta, localizados na região do Trairí potiguar e microrregião do Curimataú paraibano. Estes foram, denominados de propriedade 1 (P1) e propriedade 2 (P2), respectivamente. Na P1 se aplicaram técnicas de acordo com as análises de solo e agua e, a P2 faz uso de conhecimentos empíricos. Em ambas as propriedades foram utilizadas irrigação e controle de pragas e doenças. Nas propriedades, os produtores escolheram quinze plantas que visualmente aparentavam, segundo os produtores, maior resistência, produtividade e precocidade ou longevidade. A coleta de dados foi feita em duas etapas. A primeira foi através contagem de frutos por planta e o diâmetro médio das mesmas. A segunda foi à colheita de cinco frutos por planta que foram encaminhados para análises físicas em laboratório, onde foram medidos, pesados, extraído à polpa, medido a espessura da casca, pesado e contado as sementes, além de quantificado a percentagem de polpa e classificado os frutos. Portanto, conclui-se que o P1 foi o mais indicado para o mercado in natura, por apresentar os melhores rendimentos em número e produção de frutos, e melhores dados biométricos, embora o rendimento em polpa tenha sido inferior, podendo superar-se devido às outras características.

Palavras-chave: Maracujazeiro; Qualidade; Seleção.

\section{INTRODUÇÃO}

O maracujá é uma fruteira que pertence à família das Passifloraceae originária da América tropical, possuindo mais de 150 espécies utilizadas para diversas finalidades, desde alimentícias, medicinais, até ornamentais. As espécies mais cultivadas no Brasil e no mundo são de maracujá-amarelo (Passiflora edulis Sims. f. flavicarpa Deg.), maracujá-roxo (Passiflora edulis Sims.) e maracujá-doce (Passiflora alata Curtis). Apesar da grande variedade de espécies atribuídas à família Passifloracea, a espécie de maracujá-amarelo ou azedo representa a quase totalidade do volume comercializado mundialmente (PIRIS et al., 2011).

Nas últimas décadas tem sido observado um acréscimo da área plantada com maracujazeiro no Brasil em torno de 75\%, em apenas seis anos (MELETTI, 2011). Com essa perspectiva, o maracujá vem sobressaindo-se sobre outras culturas como uma nova forma de 
manter uma agricultura familiar e sustentável. Além disso, os mercados de suco e de fruta in natura, dois segmentos diferenciados, têm crescido substancialmente nos últimos anos, apresentando, por consequência, uma evolução da área cultivada com elevação da produção, quando comparada com as décadas anteriores (COSTA et al., 2008).

O maracujá mais consumido na forma de sucos foi considerado uma fruta de pomar doméstico durante muitos anos, em razão de suas propriedades medicinais. Seu valor comercial foi descoberto bem mais tarde, no final da década de 60, quando os primeiros pomares paulistas foram instalados. Historicamente, trata-se de um curto período de produção, representado por apenas 40 anos, bastante significativo ao se considerar que o país é o maior produtor mundial de maracujá-amarelo, há mais de duas décadas (MELETTI, 2011).

Por conseguinte, o maracujazeiro, por ser uma planta tropical típica, exige grande intensidade luminosa, que associada a outros fatores garante um vigoroso crescimento vegetativo, pleno florescimento, maior vingamento de frutos, frutificação abundante e frutos de alta qualidade (COSTA et al., 2008), por isso a necessidade de conhecimentos técnico, pois, segundo Amaro e Monteiro (2001) a expansão da cultura do maracujá exige uma tecnologia de produção adequada, ainda que, alguns problemas na produção desta frutífera são comumente encontrados, provocando assim, uma baixa produtividade no rendimento e na qualidade dos frutos, destacando a necessidade de pesquisas para o desenvolvimento de variedades melhoradas e para melhor definir tecnologias de produção, capazes de proporcionar o aumento da produtividade, a possibilidade do aumento na sobrevida da cultura e a melhoria da qualidade dos frutos, que são essenciais para o sucesso do agricultor (COIMBRA et al., 2012).

Com o objetivo de comparar duas formas de condução da cultura do maracujá, se realizou esse trabalho.

\section{MATERIAL E MÉTODOS}

O material vegetal utilizado foi o maracujá-amarelo azedo (Passiflora edulis Sims. f flavicarpa Deg.). O experimento foi conduzido em duas propriedades distintas localizadas nas Cidades de Coronel Ezequiel-RN, na Região do Trairi Potiguar e Nova Floresta-PB, região do Curimataú Paraibano. Para o estudo de comparação entre as propriedades, as mesmas foram separadas em:

Propriedade 1 (P1), situada no Sitio Gurjaú, Coronel Ezequiel-RN, localizada a $678 \mathrm{~m}$ de altitude, latitude $6^{\circ} 23^{\prime} 34,69$ ” S e longitude $36^{\circ} 10^{\prime} 30,46^{\prime \prime} \mathrm{W}$.

Nesta plantação o proprietário realizou o plantio dentro das indicações sugeridas pela análise de solo e agua utilizando a correção do solo, a aplicação de adubos químico e orgânico, além dos defensivos agrícolas indicados, também utilizou muda de qualidade e fez uso da técnica de formação da cortina, indicada para uma boa formação dos ramos de frutificação. O espaçamento da cultura foi de 2,5 x $3 \mathrm{~m}$, em estacas de madeira de 1,80 m de altura, utilizando um fio de arame $\mathrm{n}^{\circ} 12$ e, orientação Norte/Sul, aconselhada para a cultura do maracujá. As plantas foram produzidas a partir de sementes escolhidas no próprio plantio, coletadas das plantas com maior produção.

Propriedade 2 (P2), situada no Sítio Flores de Cima, Nova Floresta-PB, a 666m de altitude, latitude $6^{\circ} 26^{\prime}$ 20,2” S e longitude $36^{\circ} 13$ ' 12,3” W.

O produtor fazendo uso de seus conhecimentos adquiridos ao largo dos anos de cultivo, não utilizou indicações técnicas baseadas em análise de solo e água, porque não a fez. Suas mudas foram compradas a terceiros, na própria região, sem a seleção de sementes e tanto a irrigação, adubação e controle de pragas e doenças foram feitas de acordo com seus conhecimentos ou baseando-se nas informações de outros produtores da região. $\mathrm{O}$ uso da técnica de poda só foi feita a de formação não realizando a formação da cortina, poda de frutificação.

Quanto à polinização, ambos os produtores utilizaram a polinização manual devido à baixa incidência do polinizador natural, o mamangava. 
Em cada propriedade, 15 plantas foram selecionadas pelos produtores com características de produtividade e, para cada uma delas, foram coletados o diâmetro do caule, o número de frutos/planta e a produção média (kg/planta). Em seguida, foram coletados cinco frutos por planta e, em laboratório, foram determinadas as características físicas dos mesmos.

As características físicas estudadas foram peso, comprimento e diâmetro do fruto, e o peso e espessura da casca, número e peso de sementes, e rendimento em polpa (g e \%). Também se determinou a classificação dos frutos em função do seu diâmetro. A classificação diamétrica dos frutos de maior tamanho (diâmetro superior a $75 \mathrm{~mm}$ ) (C4 e C5) foi realizada de acordo com as normas de classificação do Programa Brasileiro de Melhoria dos Padrões Comerciais e de Embalagens do maracujá-azedo (CEAGESP, 2001), indicados para o mercado in natura.

Os dados coletados e processados foram submetidos à análise de variância, a 5\% de probabilidade, por meio do aplicativo computacional SPSS Inc. ${ }^{\circledR}$ Win TM, vs 19,0.

\section{RESULTADOS E DISCUSSÃO}

O Plantio P1 apresentou os melhores resultados, tanto com relação ao diâmetro médio das plantas, número e produção de frutos por planta $(\mathrm{kg})$ do maracujá-amarelo, quando comparado com o plantio P2 (Tabela 1). Esses resultados podem estar relacionados ao maior vigor das plantas cultivadas nas condições do P1, maior diâmetro médio do caule $(2,39 \mathrm{~cm}) \mathrm{com}$ relação ao P2 $(1,81 \mathrm{~cm})$, assemelhando-se aos encontrados por Santos et al. (2016) que foram 2,10, 1,68, 1,99 e 2,63 cm. Para números de frutos e produção por planta (kg), esses dados foram inferiores aos encontrados por Kist; Manick; Boaro (1995), com 153 frutos e 82,24 kg.planta ${ }^{-1}$, respectivamente. Vale salientar que os dados deste trabalho correspondem apenas a primeira colheita do ano, podendo ser essa a explicação do menor rendimento destes plantios.

Tabela 1. Dados médios em diâmetro do caule das plantas, número de frutos e produção (kg.planta ${ }^{-1}$ ) do maracujá amarelo, cultivados em dois plantios diferentes.

\begin{tabular}{llll}
\hline Plantio & Diâmetro $(\mathrm{cm})$ & $\mathrm{N}^{\circ}$ Frutos . Planta $^{-1}$ & Produção . Planta $^{-1}(\mathrm{~kg})$ \\
\hline P1 & $2,39 \mathrm{a}$ & $65 \mathrm{a}$ & $17,14 \mathrm{a}$ \\
P2 & $1,81 \mathrm{~b}$ & $17 \mathrm{~b}$ & $3,34 \mathrm{~b}$ \\
\hline
\end{tabular}

Médias seguida de letras distintas na colona diferem entre si, ao nível de 5\% de probabilidade.

Os dados biométricos dos frutos cultivados no plantio P1 apresentaram as melhores médias com relação ao plantio P2, exceto no que se refere à espessura da casca do fruto, que foi superior no plantio P2 (Tabela 02). Os pesos dos frutos obtidos em ambas as propriedades foram superiores aos do trabalho realizado por Farias et al. (2007), onde o valor foi de 177,28 g. Com relação ao peso das cascas de frutos cultivados sob o plantio P2, observou-se que os dados foram semelhantes aos obtidos por Oliveira et al. (2002), exercendo uma variação de 97,5-29,8. Já com respeito ao peso das sementes, frutos coletados tanto na P1 quanto na P2 tiveram pesos de sementes dentro da variação de 36,1-8,3 também encontrada por Oliveira et al. (2002). Os valores obtidos para peso de polpa de frutos obtidos em P1 $(87,52)$ e em P2 $(71,25)$ expressam semelhança entre seus pesos. Quanto à espessura, os frutos da propriedade $\mathrm{P} 2$ apresentaram maior espessura $(9,34 \mathrm{~mm})$, resultando superior aos coletados em P1 $(8,33 \mathrm{~mm})$ e aos resultados obtidos por Farias et al. (2007), que são de 7,06 mm. O rendimento em polpa de frutos cultivados no plantio P2 foi superior, tendo superado também a Amaro e Monteiro (2001), com $31,4 \%$. 
Tabela 2. Dados biométricos de frutos de maracujá amarelo, cultivados em dois plantios diferentes.

\begin{tabular}{lcccccc}
\hline Plantio & $\begin{array}{c}\text { Peso Fruto } \\
(\mathrm{g})\end{array}$ & $\begin{array}{c}\text { Casca } \\
(\mathrm{g})\end{array}$ & $\begin{array}{c}\text { Espessura } \\
(\mathrm{mm})\end{array}$ & $\begin{array}{c}\text { Sementes } \\
(\mathrm{g})\end{array}$ & Peso Polpa (g) & Rendimento em polpa (\%) \\
\hline P1 & $269,67 \mathrm{a}$ & $150,97 \mathrm{a}$ & $8,33 \mathrm{~b}$ & $28,54 \mathrm{a}$ & $87,52 \mathrm{a}$ & $32,43 \mathrm{~b}$ \\
P2 & $190,70 \mathrm{~b}$ & $97,56 \mathrm{~b}$ & $9,34 \mathrm{a}$ & $19,11 \mathrm{~b}$ & $71,25 \mathrm{~b}$ & $37,17 \mathrm{a}$ \\
\hline
\end{tabular}

Médias seguida de letras distintas na coluna diferem entre si, ao nível de 5\% de probabilidade.

Como é possível observar a partir dos dados da Tabela 03, o comprimento e diâmetro dos frutos de maracujá obtidos na plantação P1 apresentaram valores médios significativamente superiores aos obtidos na P2, com elevado percentual (94,7\%) de frutos com classificação diamétrica para as classes C4 e C5, isto é, frutos com diâmetro superior a $75 \mathrm{~mm}$, de acordo com a classificação da CEAGESP (2001). Isso quer dizer que estes frutos são indicados para o mercado in natura e podem alcançar melhores preços no mercado. Por outro lado, somente $54,4 \%$ dos frutos obtidos na P2 apresentaram classificação superior (C4/C5), podendo os demais ser destinados para o mercado de extração de sucos. Os valores de comprimento e diâmetro da P1 foram superiores aos encontrados por Farias et al. (2007) que obteve comprimento de frutos com 89,82 mm e diâmetros de 76,91 mm, sendo mais similares aos encontrados em frutos da plantação P2.

Tabela 3. Média de comprimento, diâmetro e classificação diamétrica (C4 e C5) dos frutos de maracujáamarelo azedo cultivados em dois plantios diferentes.

\begin{tabular}{lccc}
\hline Plantio & $\begin{array}{c}\text { Comprimento } \\
(\mathrm{mm})\end{array}$ & $\begin{array}{c}\text { Diâmetro } \\
(\mathrm{mm})\end{array}$ & $\begin{array}{c}\text { Classificação (\%) } \\
\text { Classes C4 e C5 }\end{array}$ \\
\hline P1 & $106,14 \mathrm{a}$ & $87,97 \mathrm{a}$ & $94,7 \%$ a \\
P2 & $87,51 \mathrm{~b}$ & $77,12 \mathrm{~b}$ & $57,4 \% \mathrm{~b}$ \\
\hline
\end{tabular}

Médias seguidas de letras distintas na coluna diferem entre si, significativamente, ao nível de 5\% de probabilidade. Os dados apresentados em \% são reais, sendo a análise estatística realizada com os dados transformados em arcoseno.

\section{CONCLUSÃO}

As diferenças entre os dois cultivos influenciam em importantes características de produção do maracujazeiro, sendo o plantio P1 mais indicado por apresentar os melhores rendimentos em número e produção de frutos, e melhores dados biométricos dos frutos, além de uma maior percentagem de frutos indicados para o mercado in natura.

\section{REFERÊNCIAS}

AMARO, A. P.; MONTEIRO, M. Rendimento de extração da polpa e características físicoquímicas do maracujá amarelo (Passiflora edulis Sims. f. flavicarpa Deg.) produzido por cultivo orgânico e convencional em relação à cor da casca. Alimentos e Nutrição, v. 12, n. 1, p. 171-184, 2009. 
CEAGESP - Companhia de Entrepostos e Armazéns Gerais de São Paulo. Classificação do maracujá (Passiflora edulis Sims.). Programa Brasileiro para a Melhoria dos Padrões Comerciais e de Embalagens do Maracujá-Azedo. 2001. Disponível em: $<$ http://www.ceagesp.com.br>. Acesso em: 23 abr. 2016.

COIMBRA, K. D. G.; PEIXOTO, J. R.; SOUSA, M. A. D. F. D.; JUNQUEIRA, N. T. V. Productivity and quality of fruits of 14 progenies of yellow passion fruit cultivated in Federal Distric. Revista Brasileira de Fruticultura, v. 34, n. 4, p. 1121-1128, 2012.

COSTA, A. F. S.; COSTA, A. N.; VENTURA, J. A.; FANTON, C. J.; LIMA, I. M.; CAETANO, L. C. S.; SANTANA, E. N. Recomendações técnicas para o cultivo do maracujazeiro. Vitória: Incaper, 2008.

FARIAS, J. F.; SILVA, L. J. B.; ARAÚJO NETO, S. E.; MENDONÇA. V. Qualidade do maracujá-amarelo comercializado em Rio Branco, Acre. Revista Caatinga, v. 20, n. 3, p. 196202, 2007.

KIST, H. G. K.; MANICK, I.; BOARO, A. Efeito de seis espaçamentos de plantio na produção de maracujá-amarelo (Passiflora edulis f. flavicarpa Deg.) em Porto Lucena, RS. Pesquisa Agropecuária Gaúcha, Porto Alegre, v. 1, n. 1, p. 21-26, 1995.

MELETTI, L. M. M. Avanços na cultura do maracujá no Brasil. Revista Brasileira de Fruticultura, Jaboticabal, v. 33, n. spe1, p. 83-91, 2011.

OLIVEIRA, L. F.; NASCIMENTO, M. S. F.; BORGES, S. V.; RIBEIRO, P. C. N.; RUBANC, V. R. Aproveitamento alternativo da casca do maracujá-amarelo. Ciência Tecnologia Alimento, v. 22, n. 3, p. 259-262, 2002.

PIRIS, M. M.; SÃO JOSÉ, A. R.; CONCEIÇÃO, A. O. Maracujá: avanços tecnológicos e sustentabilidade. Ilhéus: Editus, 2011.

SANTOS, C. H. B.; CRUZ NETO, A. J.; SOARES, T. L.; OLIVEIRA, E. J.; JESUS, O. N.; GIRARDI, E. U. Porta-enxertos e fixadores de enxerto para enxertia hipocotiledonar de maracujazeiro azedo. Ciência Rural, v. 46, $\quad$ n. 1, p. 30-35, 2016. http://dx.doi.org/10.1590/0103-8478cr20140154 